\title{
MODULAR APPROACH TO ANALYSIS OF CHEMICALLY RECUPERATED GAS TURBINE CYCLES
}

\author{
C. CARCASCI, ${ }^{\dagger}$ B. FACCHINI ${ }^{\dagger}$ and S. HARVEY ${ }^{\ddagger *}$ \\ "University of Florence, "Sergio Stecco" Department of Energy Engineering, via Santa Marta 3, \\ 50139 Florence, Italy \\ ${ }^{\ddagger}$ Chalmers Institute of Technology, Dept of Heat and Power Technology, 41296 Göteborg, Sweden
}

\begin{abstract}
Current research programmes such as the CAGT programme investigate the opportunity for advanced power generation cycles based on state-of-the-art aeroderivative gas turbine technology. Such cycles would be primarily aimed at intermediate duty applications. Compared to industrial gas turbines, aeroderivatives offer high simple cycle efficiency, and the capability to start quickly and frequently without a significant maintenance cost penalty. A key element for high system performance is the development of improved heat recovery systems, leading to advanced cycles such as the humid air turbine (HAT) cycle, the chemically recuperated gas turbine (CRGT) cycle and the Kalina combined cycle. When used in combination with advanced technologies and components, screening studies conducted by research programmes such as the CAGT programme predict that such advanced cycles could theoretically lead to net cycle efficiencies exceeding $60 \%$. In this paper, the authors present the application of the modular approach to cycle simulation and performance predictions of CRGT cycles. The paper first presents the modular simulation code concept and the main characteristics of CRGT cycles. The paper next discusses the development of the methane-steam reformer unit model used for the simulations. The modular code is then used to compute performance characteristics of a simple CRGT cycle and a reheat CRGT cycle, both based on the General Electric LM6000 aeroderivative gas turbine. (C) 1998 Elsevier Science Ltd. All rights reserved
\end{abstract}

Chemical recuperation Reheat gas turbine Methane-steam reforming CRGT cycles Gas turbine cycle simulation

\section{INTRODUCTION}

\section{Chemical recuperation}

Chemical recuperation is one of several innovative concepts applicable to natural gas-fired gas turbine-based power generation cycles. The concept has made considerable progress over the past few years with the support of the California Energy Commission [1]. The idea of improving heat engine performance by using a chemical reaction to recover waste heat was first discussed by Olmsted and Grimes [2]. The chemically recuperated gas turbine is an extension of the steam-injected gas turbine concept, in which exhaust heat is used to raise steam which is subsequently injected directly into the gas turbine combustor. Figure 1 illustrates the CRGT concept. Exhaust heat is recovered in a heat recovery steam generator (HRSG) where the superheater section is replaced by a methane-steam reformer (MSR). The natural gas fuel is mixed with the generated steam and fed into the MSR. In the reformer, the mixture of natural gas and steam is heated by the combustion turbine exhaust, and an endothermic reaction occurs between the methane and the steam. The reaction requires the presence of a nickel-based catalyst, and results in the production of $\mathrm{H}_{2}, \mathrm{CO}_{2}$ and $\mathrm{CO}$. Complete conversion of methane in this manner could potentially increase the effective fuel heating value by approximately $30 \%$. Thus, the methane/steam mixture absorbs heat thermally (as it is heated) and chemically (as the endothermic reaction proceeds), resulting in a larger potential recuperation of exhaust energy than can be obtained by conventional recuperation, which recovers energy by heat alone. The reformed fuel, containing $\mathrm{CO}, \mathrm{CO}_{2}, \mathrm{H}_{2}$, excess steam and unconverted methane, is then fed into the turbine combustor.

*To whom correspondence should be addressed. Tel.: (+46) 31.772.8531; Fax: (+46) 31.82.1928; E-mail: simon.harvey @ hpt.chalmers.se. 


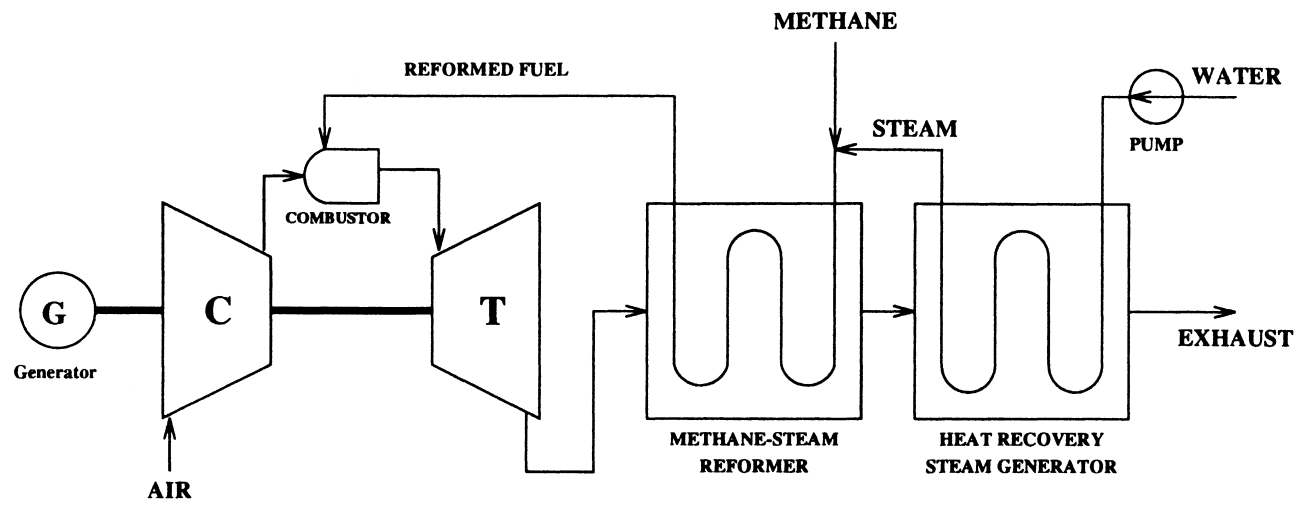

Fig. 1. Chemically recuperated gas turbine concept.

The chemically recuperated gas turbine cycle has received relatively little attention from power generation cycle researchers compared to other innovative gas turbine cycles such as the humid air turbine (HAT cycle), the steam injected gas turbine (STIG cycle), or the Kalina combined cycle. The CRGT cycle was considered by the CAGT collaborative advanced gas turbine programme [3]. This programme was initiated to promote R\&D programmes for development of high-performance gas turbine cycles for intermediate and base load applications, using stateof-the-art aeroderivative gas turbine technologies. However, in the screening phases of this programme, only a few of the possible CRGT cycle configurations were considered. Furthermore, no results were presented for off-design performance, which is a key comparison criterion for future intermediate load high-performance cycles. Along the same lines, Lloyd [4] presented a detailed study of the thermodynamics of CRGT cycles, together with the results of a number of cycle simulations. Again, the results presented are only for design-point operation, and no results are presented for part-load operation.

\section{Modular approach for thermodynamic analysis of CRGT power plants}

Given the complexity of the CRGT plant configurations, such studies require the development of adequate calculation tools for plant simulation and performance predictions, with particular emphasis placed on partial load performance. In this study we present the development of the required tools for simulation of CRGT plants, based on the modular approach developed by Carcasci and Facchini [5]. The current paper is restricted to development of tools for thermodynamic analysis of CRGT cycles. Further work is currently under way to extend this analysis to design and off-design calculations for this type of cycle.

A complete presentation of the modular approach used by the authors for power plant simulation may be found in a previous paper [5]. The method is summarized below.

Generally, power plant simulations are performed using dedicated codes with fixed input data, or with limited variations. In contrast, generalized power plant analysis can be ensured by a modular approach. A modular simulation code must therefore be able to:

-create a new power plant configuration, without creating a new source program;

-handle any combination of input data, provided that there is a sufficient and consistent number of parameters for plant simulation;

-determine the characteristic parameters of the elementary components, when an increased number of boundary input data are fixed.

The development of a modular code has been studied by a number of researchers using different approaches. The method used by the authors in this work is based on a full implicit linear approach, where the code reduces the non-linear equation system to a linear system with variable coefficients, then all equations are solved simultaneously using a classic matrix method. The power plant configuration is defined by connecting a number of elementary components representing different unit operations such as compressors, pumps, combustion chambers, splitters, mixers, etc. Therefore, in each elementary component there are mass and energy flows which 


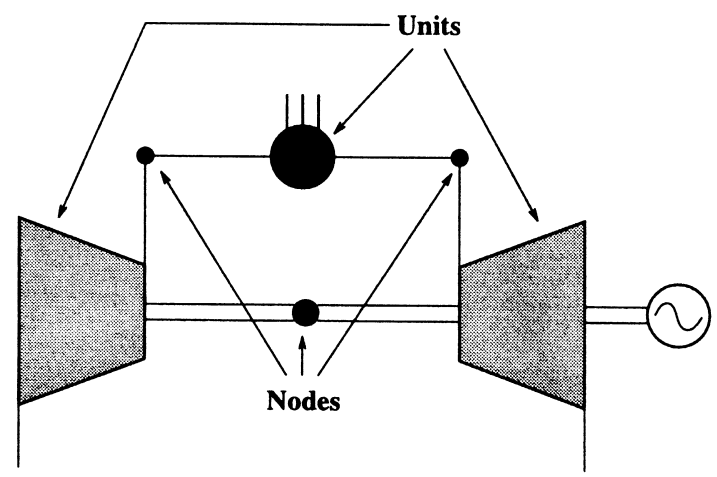

Fig. 2. Modular code: example of a power plant.

undergo chemical and thermodynamic transformations. In the mathematical model, each such component will be referred to as a unit (see Fig. 2). The units are connected by:

-streams, which are connections allowing the transport of mass between two units;

-mechanical energy links, which transport mechanical energy and are characterized by a specific angular speed (e.g. a shaft).

The points connecting two units are referred to as nodes. A method to provide sufficient information to describe the flow in each node of the plant must be determined. Each unit is thus defined as a black box capable of simulating a given thermodynamic transformation. Obviously, certain internal characteristics of the components and certain properties of the flow in some nodes will be known (data of the power plant system). However, none of these is considered essential and in this respect, this modular approach is more general than other semi-parallel or sequential methods. For a general and flexible solution method, the use of a linear system is advantageous. Therefore, all the equations defining the power plant are linearized, and their coefficients updated in the course of the calculation. The resulting assembled matrix system dimension is then reduced to optimize calculation time, and the system is then solved.

\section{DEVELOPMENT OF A METHANE-STEAM REFORMER MODEL}

The key new component model defined in the course of this study is the methane-steam reformer (MSR) model. In this section we detail the equations used to define MSR operation. Figure 3 shows the MSR component. The hot turbine exhaust gas enters by input IN 1. The turbine gas is cooled as heat is transferred to the cold side of the reactor, in which the endothermic methane-steam reforming reactions occur. The turbine gas leaves the MSR by output

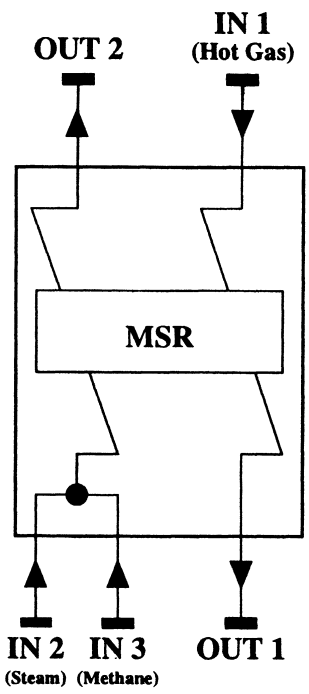

Fig. 3. Modular code: methane-steam reformer component. 
node OUT 1. On the cold side, steam and methane enter the component separately by input nodes IN 2 and IN 3, respectively. The mixing of the two streams occurs within the component. The mix then enters the reaction zone, and the reformed gas stream leaves the component by exit node OUT 2.

Within the MSR reaction zone, the methane and steam react according to the following reactions:

$$
\begin{gathered}
\mathrm{CH}_{4}+\mathrm{H}_{2} \mathrm{O}=\mathrm{CO}+3 \mathrm{H}_{2} \\
\mathrm{CO}+\mathrm{H}_{2} \mathrm{O}=\mathrm{CO}_{2}+\mathrm{H}_{2}
\end{gathered}
$$

Methane conversion in the reformer is restricted by the chemical equilibrium of reactions (1) and (2). Furthermore, reaction (1) is rate-limited by reaction kinetics, whereas the shift reaction (2) can be assumed to be at equilibrium for the conditions considered. The steam-to-methane ratios must be chosen sufficiently high to prevent carbon coking. Typical steam-to-methane ratios are in the 3 to 5 range for industrial steam reformers [1], widely used for hydrogen production for ammonia or methanol synthesis. Reaction (1) proceeds in the presence of a catalyst, usually nickel-based. For the low temperature reforming considered in this case, it is necessary to use catalysts that are active at low temperatures. According to [1], catalysts can be found that are sufficiently active for temperatures above $600 \mathrm{~K}$. For a thermodynamic cycle analysis, the chemical non-equilibrium effects due to reaction kinetics can be modelled using the chemical approach to equilibrium $\Delta T_{\text {eq }}$. For currently available catalysts, $\Delta T_{\text {eq }}$ is given by the following correlations in [4]:

$$
\begin{gathered}
\Delta T_{\mathrm{eq}}=0 \quad \text { if } \quad T_{\mathrm{out}, 2} \geq 923 \mathrm{~K} \\
\Delta T_{\mathrm{eq}}=43.33\left(1.0-\frac{T_{\mathrm{out}, 2}-273}{650}\right) \quad \text { if } \quad T_{\mathrm{out}, 2}<923 \mathrm{~K}
\end{gathered}
$$

where $T_{\text {out }, 2}$ refers to the temperature of the reformed fuel stream at the exit of the reformer. $T_{\mathrm{out}, 2}$ can be computed by imposing a hot-side temperature approach (i.e. $T_{\mathrm{in}, 1}-T_{\mathrm{out}, 2}$ ) for the component. According to the definition of $\Delta T_{\mathrm{eq}}$, the composition at node OUT 2 can be computed by solving for the chemical equilibrium composition at temperature $\mathrm{T}_{\text {out }, 2}-\Delta \mathrm{T}_{\text {eq }}$, based on the feed composition entering the MSR reactor through inlet nodes IN 2 and IN 3. The overall pseudo-reaction can be written as:

$$
\alpha_{1} \mathrm{CH}_{4}+\alpha_{2} \mathrm{H}_{2} \mathrm{O}=\beta_{1} \mathrm{CH}_{4}+\beta_{2} \mathrm{CO}+\beta_{3} \mathrm{CO}_{2}+\beta_{4} \mathrm{H}_{2}+\beta_{5} \mathrm{H}_{2} \mathrm{O} .
$$

$\alpha_{1}$ and $\alpha_{2}$ are known quantities resulting from the feed quantities in inlet nodes IN 2 and IN 3 . It is thus necessary to solve for the five unknowns $\beta_{1}$ through $\beta_{5}$. Atom balances on the atomic elements $\mathrm{C}, \mathrm{H}$ and $\mathrm{O}$ yield the following three equations, respectively:

$$
\begin{gathered}
\mathrm{C} \text { atom balance : } \quad \alpha_{1}=\beta_{1}+\beta_{2}+\beta_{3} \\
\mathrm{H} \text { atom balance : } \quad 4 \alpha_{1}+2 \alpha_{2}=4 \beta_{1}+2 \beta_{4}+2 \beta_{5} \\
\mathrm{O} \text { atom balance : } \quad \alpha_{2}=\beta_{2}+2 \beta_{3}+\beta_{5} .
\end{gathered}
$$

Two more equations result from the equilibrium constants $K_{p}$ of reactions (1) and (2). The equilibrium constant $K_{p, 1}$ of the reforming reaction (1) can be written as:

$$
\begin{aligned}
K_{p, 1} & =\frac{p_{\mathrm{CO}} p_{\mathrm{H}_{2}}^{3}}{p_{\mathrm{CH}_{4}} p_{\mathrm{H}_{2} \mathrm{O}} p_{0}^{2}} \\
& =\frac{\beta_{2} \beta_{4}^{3}}{\beta_{1} \beta_{5}} \frac{1}{N_{\text {tot }}^{2}} \frac{p_{\text {out }, 2}^{2}}{p_{0}^{2}}
\end{aligned}
$$

where $N_{\text {tot }}$ denotes the total number of moles at equilibrium (i.e. $N_{\text {tot }}=\beta_{1}+\beta_{2}+\beta_{3}+\beta_{4}+\beta_{5}$ ), and $p_{0}$ denotes the reference pressure, usually taken as $1 \mathrm{~atm}$. The value of $K_{p, 1}$ at temperature 
$T$ is computed using the following correlation, taken from [6]:

$$
K_{p, \operatorname{Ref}}=\exp \left(30.688-\frac{27463}{T}\right) \text {. }
$$

Similarly, the equilibrium constant $K_{p, 2}$ of the shift reaction (2) can be written as:

$$
\begin{aligned}
K_{p, 2} & =\frac{p_{\mathrm{CO}_{2}} p_{\mathrm{H}_{2}}}{p_{\mathrm{CO}} p_{\mathrm{H}_{2} \mathrm{O}}} \\
& =\frac{\beta_{3} \beta_{4}}{\beta_{2} \beta_{5}} .
\end{aligned}
$$

The value of $K_{p, 2}$ at temperature $T$ is again computed using a correlation taken from [10]:

$$
K_{p, 2}=\exp \left(\frac{4084}{T}-3.765\right)
$$

The composition at the MSR exit can thus be computed by solving the system of equations (6)(12). The temperature used to evaluate the equilibrium constants is $T_{\text {out }, 2}-\Delta T_{\text {eq }}$. When the temperature and composition at node OUT 2 are known, it is then possible to proceed with the energy balance, thus solving for state OUT 1.

The other equations used in the MSR component model are classic heat exchanger equations, including mass balances and heat balances. The model allows for pressure drops on both sides of the heat exchanger, and allows for a heat loss between the hot and cold side flows.

The model presented is sufficient for thermodynamic cycle calculations. However, for design and off-design simulations, a more extended model must be developed, to include reactor geometry, heat transfer characteristics, pressure drop calculations, and catalyst reaction kinetics.

\section{SIMULATION RESULTS FOR CHEMICALLY RECUPERATED LM6000}

Preliminary work undertaken by the California Energy Commission [1] indicates that the optimum gas turbine-reformer combination (i.e. one yielding minimum electricity costs) would incorporate the most advanced gas generator (i.e. a state-of-the-art aeroderivative machine) with a reheat combustor package located at the power turbine inlet. One of the most advanced aeroderivative gas turbines currently available is General Electric's LM6000, derived from the CF6-80C2 turbo-fan jet engine. In this section of the paper, we present results for a chemically recuperated gas turbine cycle based on the GE LM6000 aeroderivative gas turbine. Two configurations are considered, namely a simple CRGT cycle (LM6000-CR) and a reheat CRGT cycle (LM6000-CRRH). Figures 4 and 5 show the cycle configurations considered.

All simulations were performed assuming standard ISO inlet conditions. The simulation parameters for the gas turbine were fitted to obtain good agreement with published performance data ([7], [8]) for the LM6000 aeroderivative gas turbine machine, summarized in Table 1. It is important to note that with the reformed gas fuel, the fuel mass flow required to achieve a given TIT is much higher than that required with natural gas fuel, and the mass flow through the expander is therefore much greater. In practise, the turbine can be assumed to operate under choked conditions at the expander inlet. The LM6000 expander would therefore possibly require modifications to avoid pushing the compressor too near its surge limit when operating in CRGT mode. Alternatively, the TIT might be reduced to achieve an acceptable exhaust flow. Such design modifications are not accounted for in the simulations presented in this paper. It should however be noted that for the cycles presented, the increased mass flowrate in the turbine is lower than that encountered in steam-injected gas turbine (STIG) type applications. The implementation of a STIG configuration on an existing aeroderivative gas turbine usually requires only minor modifications, so we assume in this study that implementation of the CRGT cycle would also only require minor modifications of an existing aeroderivative machine.

Table 2 summarizes the simulation parameters used in the fuel reforming section of the cycle. An important parameter is the combustor fuel port pressure loss. For fuel flow control reasons, the pressure drop through the fuel inlet port is usually high in gas turbines, on the order of 


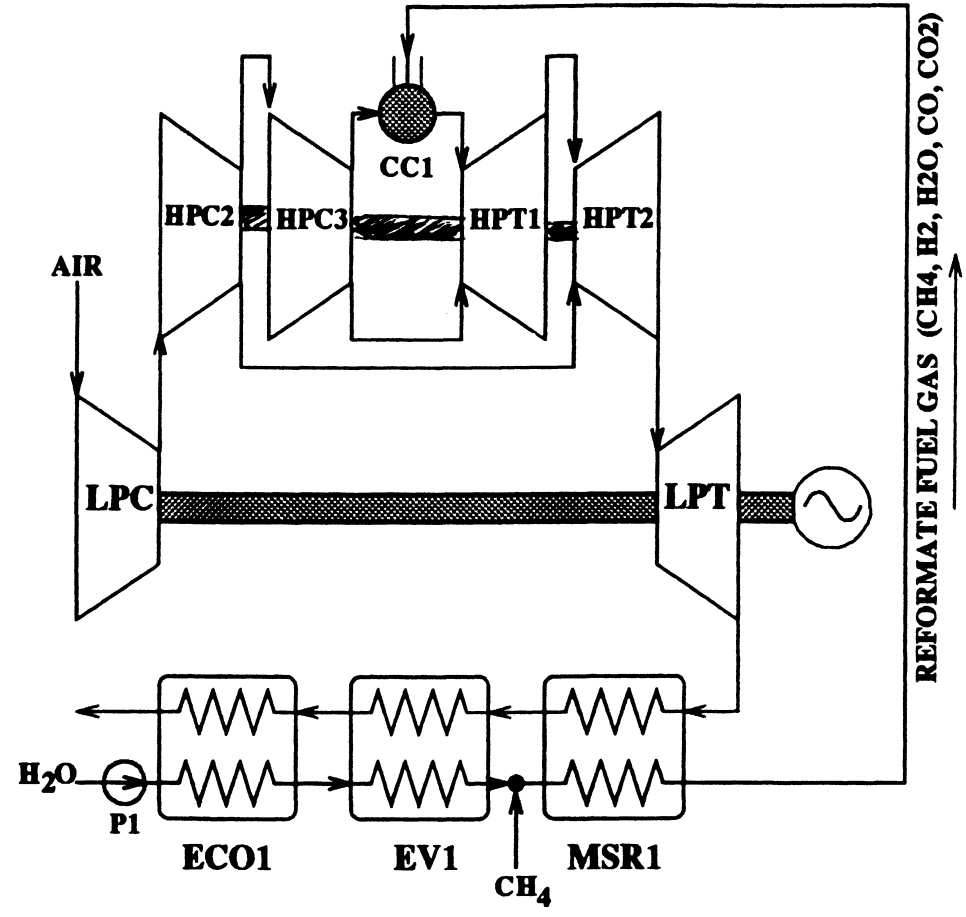

Fig. 4. Chemically recuperated LM6000 GT: cycle configuration.

$40 \%$ or higher. Such a high pressure drop at this point of the cycle has a very negative impact on cycle performance for a CRGT cycle. A similar problem arises for IGCC cycles and integrated biomass gasification GT cycles. A recent paper by Larson and Hughes [9] indicates that General Electric has patented an open-loop gas turbine control strategy that allows the fuel valve to operate in the full open position, displacing the fuel flow control problem to the

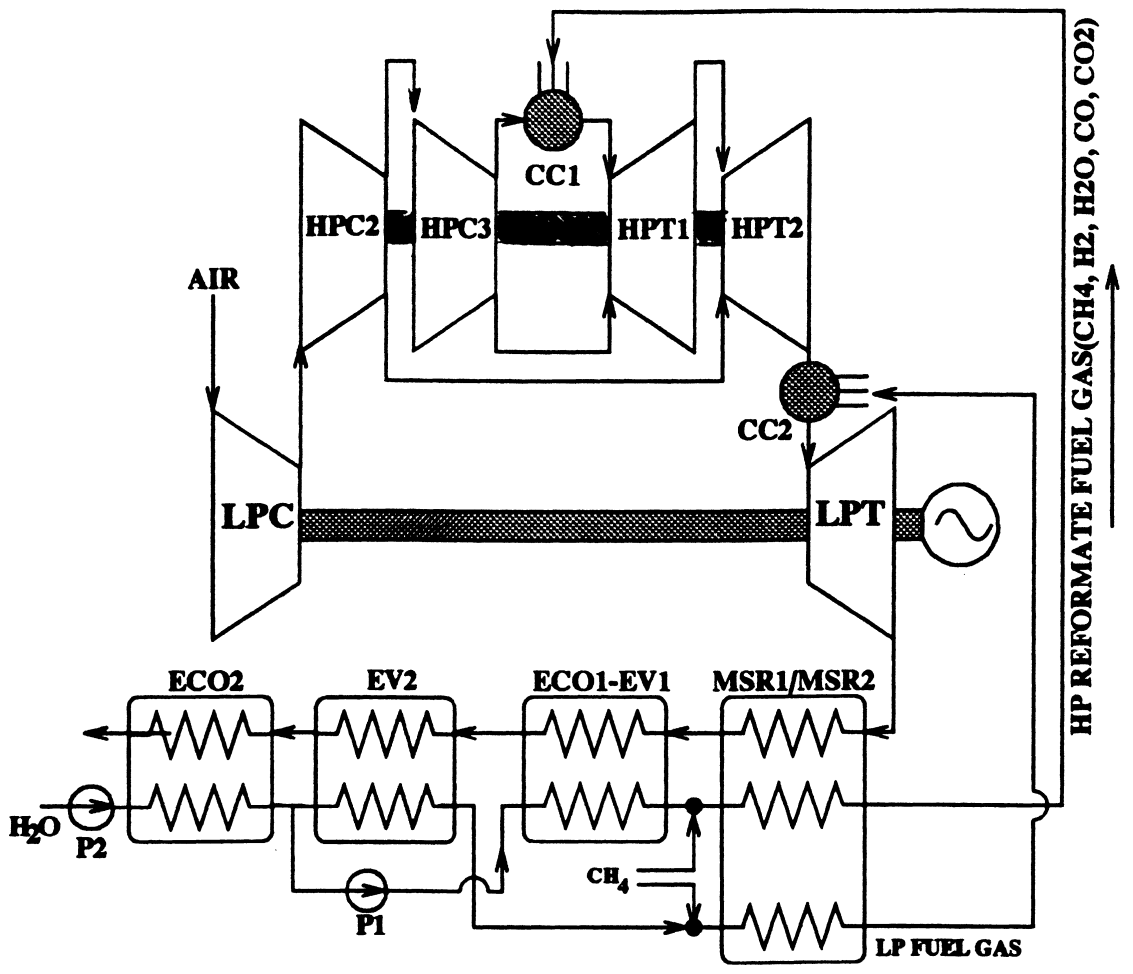

Fig. 5. Chemically recuperated reheat LM6000 GT: cycle configuration. 
Table 1. Published performance data for the LM6000

\begin{tabular}{ll}
\hline$\dot{m}_{\text {exh }}:$ & $124.7 \mathrm{~kg} / \mathrm{s}$ \\
$T_{\text {exh: }}$ & $736.6 \mathrm{~K}$ \\
Compression ratio: & $30.0: 1$ \\
Net power: & $40.7 \mathrm{MW}$ \\
Net efficiency: & $40.1 \%$ \\
\hline
\end{tabular}

Table 2. Simulation parameters: cycle reforming section

\begin{tabular}{llc}
\hline MSR: & Cold side pressure loss & $10 \%$ \\
& Hot end temperature approach & $30 \mathrm{~K}$ \\
Evaporator: & Heat losses & $0.5 \%$ \\
& Cold side pressure loss & $5 \%$ \\
Economizer: & Heat losses & $0.5 \%$ \\
& Cold side pressure loss & $5 \%$ \\
Combustor: & Heat losses & $0.5 \%$ \\
\hline
\end{tabular}

reformer fuel injection point, where the cycle efficiency penalty is considerably reduced. The fuel port pressure drop is thus reduced to its minimum (full open) value, on the order of $10 \%$. Finally, the cycle simulations presented assume that high pressure natural gas is available, and the power requirements for a fuel compressor are not accounted for.

The CRGT cycle is essentially an extension of the STIG cycle, and in this paper we therefore present results showing the variations of key cycle characteristics with the amount of water injected into the cycle, directly related to the steam/methane ratios in the cold feed to the reformers. As discussed in an earlier section, the steam-to-methane ratio in the reformer is usually between 3 and 5 in typical applications. The lower limit is to avoid carbon formation within the reactor. The higher limit for CRGT cycles is dictated by the necessity to sustain stable combustion in the gas turbine combustors. This sets an upper limit of around 6 for the steam-tomethane ratio, as discussed in [4]. This paper therefore presents results for the LM6000-CR and LM6000-CR-RH cycles as a function of steam-to-methane ratio, ranging from 3 to 6 .

\section{Results for LM6000-CR cycle}

Figure 6 shows the variation of net power output $W$ as a function of steam-to-methane ratio for the simple chemically recuperated cycle shown in Fig. 4. For comparison purposes, the figure also shows the variation of $W$ for a comparable STIG cycle with the same steam injection flowrate. The figure shows a linear increase of $W$ with steam/methane ratio, from over $49 \mathrm{MW}$ to around $62 \mathrm{MW}$ as steam/methane increases from 3 to 6 ; this to be compared to the $40.7 \mathrm{MW}$ power output of the dry LM6000 cycle. As expected, the STIG cycle shows similar behaviour,

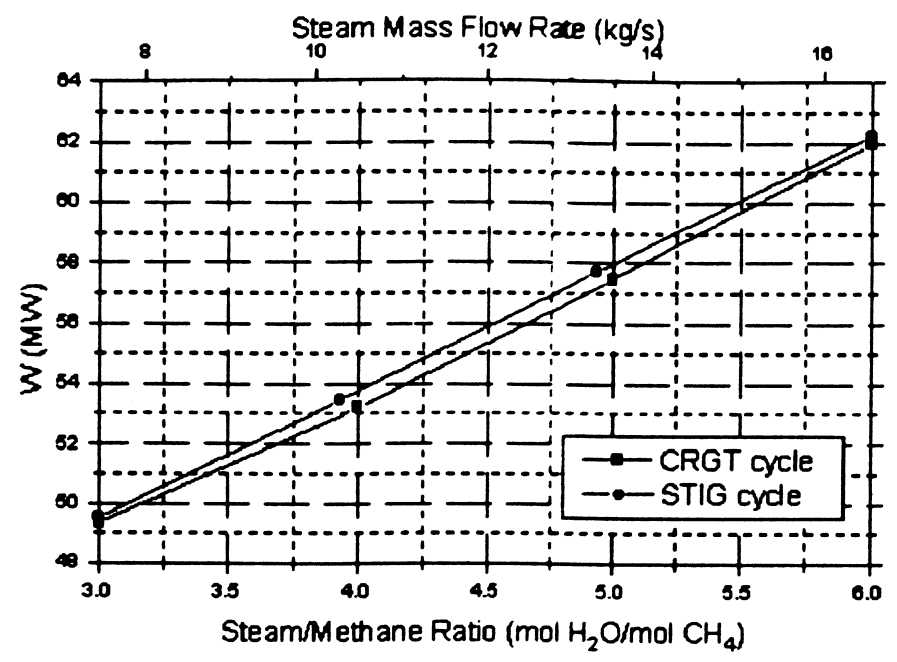

Fig. 6. LM6000-CR and LM6000-STIG cycles: net power. 


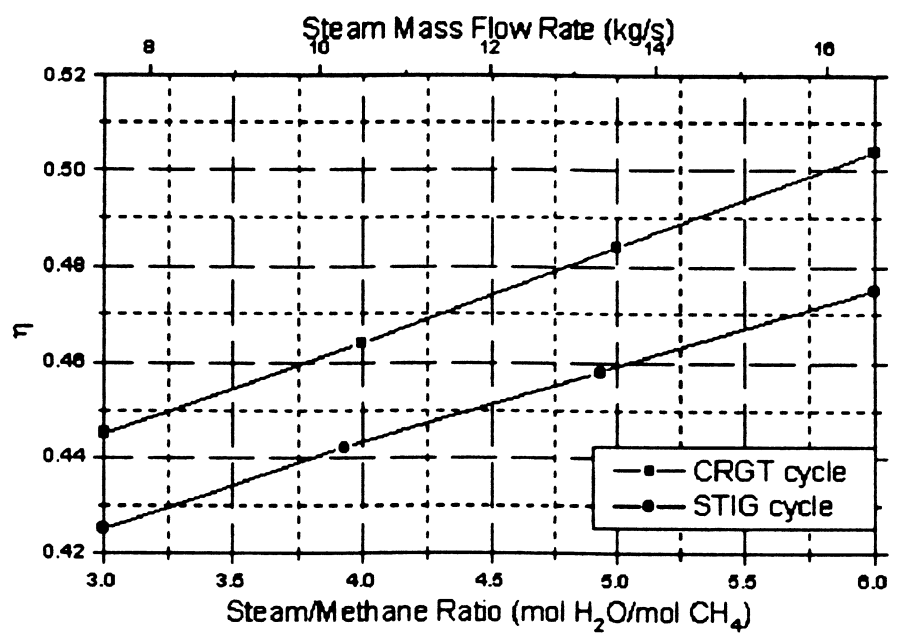

Fig. 7. LM6000-CR and LM6000-STIG cycles: net efficiency.

with a slightly higher power output for a given steam flow in the cycle. A similar linear behaviour can be observed for the cycle net efficiency in Fig. 7. The figure shows an increase in efficiency from $44.5 \%$ to around $50.5 \%$ for the CRGT cycle as the steam/methane flowrate is increased from 3 to 6 . The corresponding STIG cycle shows efficiency increasing from $42.5 \%$ to $47.5 \%$ as the steam flowrate is increased. As expected the STIG cycle therefore shows slightly higher power output at the expense of significantly decreased efficiency.

For the simple chemically recuperated LM6000 cycle, the limit to the amount of water that can be injected into the cycle is set by the minimum allowable pinch point temperature difference in the steam generator section of the cycle. Figure 8 shows the variation of $\Delta T_{P P}$ with steam/methane ratio. The upper steam/methane values are clearly not feasible, since they lead to negative $\Delta T_{P P}$ values. If $\Delta T_{P P}$ is limited to $20 \mathrm{~K}$, the steam/methane ratio of the cycle must be limited to 5.4. The non-allowable area is shaded in the figure. The figure also shows that $\Delta T_{P P}$ is not a limiting factor for the heat recovery for the STIG cycle.

One of the key reasons for the relatively small improvement in performance for the simple CRGT cycle compared to a STIG cycle is the low methane conversion in the MSR, due to a combination of factors: high reforming pressure (the equilibrium of reaction (1) is displaced towards the reactants as the pressure increases) and low reformer exit temperature due to the low turbine exhaust temperature ( $782 \mathrm{~K}$ for steam/methane equal to the limiting value of 5.4). Methane conversion varies from $8 \%$ to $14.5 \%$ as the steam/methane ratio increases from 3 to 6 (methane conversion is favored by excess steam). With a low methane conversion in the MSR,

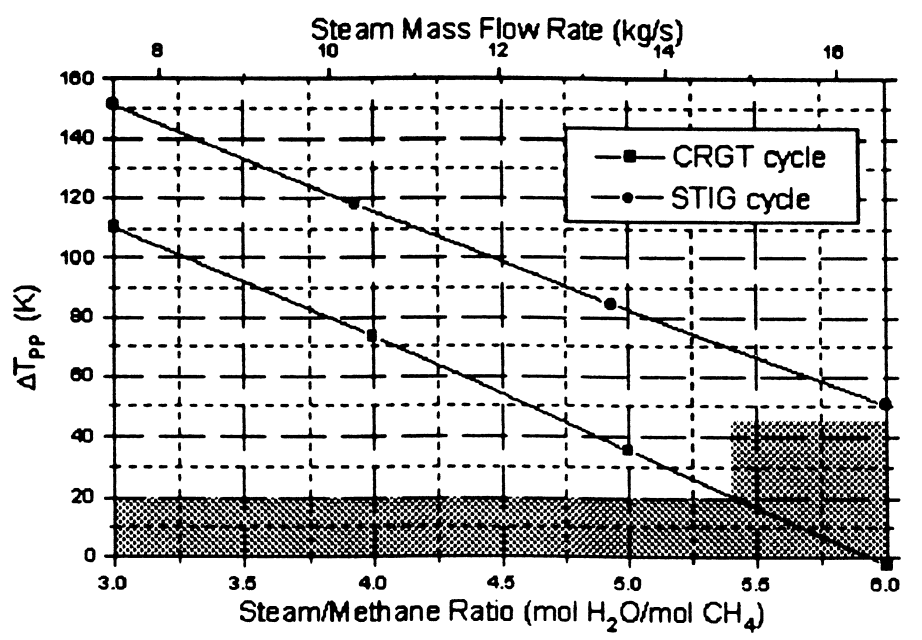

Fig. 8. LM6000-CR and LM6000-STIG cycles: steam generator pinch point $\Delta T$. 
the simple CRGT cycle behaves similarly to a modified STIG cycle in which saturated steam is mixed with the fuel, then superheated before being injected into the cycle. Thus, chemical heat recovery is low. Chemical heat recovery can be improved by adopting a reheat expansion, which will result in a higher turbine exhaust temperature, and will allow part of the fuel reforming (i.e. the fuel stream aimed at the reheat combustion process) to occur at a lower pressure, which will favor methane conversion.

To summarize, the results presented for the simple CRGT cycle confirm the results published by other authors who have worked on the CRGT cycle, such as Lloyd [4], whereby the simple CRGT cycle does not appear particularly attractive for base-load applications compared to state-of-the-art combined cycle, nor compared to STIG or HAT cycles for intermediate load or cogeneration applications. Thus it is necessary to consider more advanced CRGT cycles. The modular code is well adapted to perform such an analysis. As discussed above, one way to improve the performance of the CRGT cycle is to adopt a reheat expansion in the turbine section of the cycle. We next illustrate this by presenting results for a reheat CRGT cycle based on the LM6000 gas turbine.

\section{Results for LM6000-CR-RH reheat cycle}

Detailed simulation results for an LM6000 reheat cycle have been presented by two of the authors in [10]. The main assumptions used in their analysis are applied to a Reheat LM6000 CRGT cycle. Figure 5 shows the cycle configuration considered. The reheat combustor is placed between the LP and HP turbine sections. The reheat temperature is that of the simple LM6000 cycle which is chosen in order to limit the turbine exhaust temperature to $900 \mathrm{~K}$, thus avoiding expensive materials in the heat recovery section of the cycle, and also avoiding the necessity to cool the blades of the LP turbine. The high pressure and low pressure reformers are placed in parallel in the heat recovery section of the cycle.

Figures 9 and 10 show contour plots of net power and efficiency as a function of steam-tomethane ratio in the two reformer sections. Unlike the simple CRGT cycle, our simulations show that the limiting case results from the combustion stability limits, and the steam/methane ratio must be limited to 6 in both reformers. The figures again show essentially linear behaviour as a function of the amount of water injected into the cycle. The results are again in good agreement with similar results presented by Lloyd [9]. The results may also be compared with results presented by Harvey [11] for a reheat CRGT based on the ABB GT24/26 series reheat industrial gas turbine. The results presented by Harvey show slightly superior performance for the GT24/

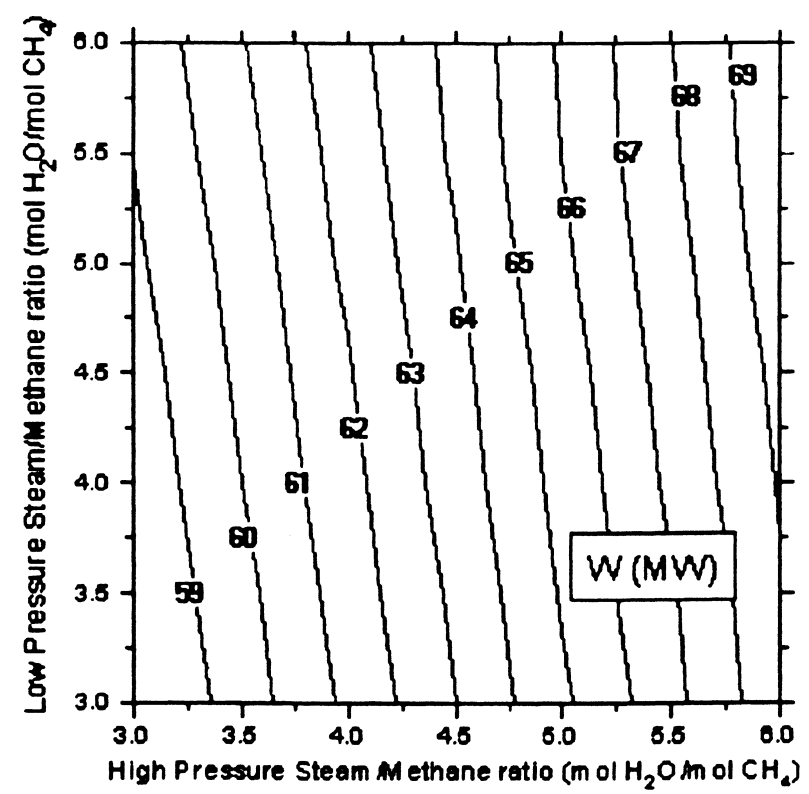

Fig. 9. LM6000-CRRH cycle: net power $W$ vs steam/methane ratio. 




Fig. 10. LM6000-CRRH. Net efficiency vs mole fraction.

26 machine. However, the assumptions made for the simulations are not identical, so care should be taken in comparing the results for the two machines. Both machines have the same overall compression ratio. However, the location of the reheat burner is very different for the two machines (reheat occurs at 15 bar for the GT24/26 compared to 8.3 bar for the Reheat LM6000). Thus reheat can occur to a much higher temperature in the GT24/26 without resorting to excessively high turbine exit temperatures (in practise the temperature at the reheat combustor exit is very close to that at the main combustor exit). However, the higher reheat temperature implies significant blade cooling in the turbine section downstream of the reheat burner, which implies expensive materials and cooling technology, as well as having a negative impact on engine performance.

Table 3 summarizes the main characteristics of the simulation results for the unrecuperated, simple CRGT and reheat CRGT LM6000 cycles. The results shown for the chemically recuperated cycles are the optimized cycle results, i.e. with maximum heat recovery accounting for water flow constraints, as discussed previously.

The performance of the LM6000-CRRH cycle is clearly superior to that of the simple CRGT cycle, both in terms of net power output and efficiency. However, the cycle efficiency is less than that announced by Westinghouse for its new Cascaded HAT (CHAT) cycle, with an announced $54.7 \%$ efficiency for a $315 \mathrm{MW}$ plant (see [12]), based on their 501F advanced turbine technology. Furthermore, the CHAT cycle has very good off-design performance characteristics, which is of prime importance for intermediate load applications, identified by the CAGT programme as the main target for innovative gas turbine cycles such as the HAT and CRGT cycles. Thus, further work is necessary to assess the off-design performance of the CRGT cycles presented in this paper.

Table 3. Summary of cycle characteristics for optimized LM6000 CRGT cycles

\begin{tabular}{lcrr}
\hline & LM6000 & LM6000-CR & LM6000-CRRH \\
\hline$W_{\text {net }}(\mathrm{MW})$ & 40.7 & 59.2 & 69.9 \\
$\dot{m}_{\text {air }}(\mathrm{kg} / \mathrm{s})$ & 122.7 & 122.7 & 122.7 \\
$\dot{m}_{\text {exhaust }}(\mathrm{kg} / \mathrm{s})$ & 124.7 & 139.7 & 143.7 \\
$\dot{m}_{\mathrm{H}_{2}} \mathrm{O}(\mathrm{kg} / \mathrm{s})$ & - & 14.6 & 18.4 \\
$T_{\text {stack }}(\mathrm{K})$ & 736.6 & 450.0 & 417.6 \\
Net efficiency $(\%)$ & 40.1 & 49.2 & 51.3 \\
\hline
\end{tabular}




\section{CONCLUSIONS}

In this paper, the modular code for power plant cycle performance analysis developed at the Dipartimento di Energetica "S.Stecco" at the University of Florence was presented. The authors presented an extension of the code to include a methane-steam reformer heat recovery unit, enabling simulation of chemically recuperated gas turbine cycles. The code was then used to simulate a chemically recuperated LM6000 gas turbine, showing how the base cycle performance ( $40.7 \mathrm{MW}$ at $40.1 \%$ efficiency) could be improved by adopting chemical recuperation and reheat expansion, yielding a net power output of $69.9 \mathrm{MW}$ at $51.3 \%$ efficiency.

Such cycles are aimed at the intermediate load market, where they must compete with the HAT cycle, which shows superior efficiency $(54.7 \%$ for the Westinghouse CHAT cycle), and excellent off-design performance.

Further work is necessary to evaluate other high-performance CRGT cycle configurations, in particular intercooled cycles. The MSR unit for the modular code must also be extended to allow design and off-design cycle calculations, allowing the CRGT cycle to be compared with the HAT cycle on the basis of off-design behaviour.

\section{REFERENCES}

1. Janes, J., Chemically recuperated gas turbine. California Energy Commission Staff Report P500-92-015, 1992.

2. Olmsted, J. H. and Grimes, P. G., Heat engine efficiency enhancement-through chemical recovery of waste heat, in Proceedings, 7th Intersociety Energy Conversion Engg. Conf., 1972, pp. 241-248.

3. Davidson, B., Dohner, C., Hay, III G. and Hollenbacher, R., The intercooled aeroderivative gas turbine-new technology for a rapidly changing electric market, CAGT Program Progress Status Report, 1995.

4. Lloyd, A., Thermodynamics of chemically recuperated gas turbines. M.Sc. Thesis, Center for Energy and Environmental Studies, Princeton University, USA, 1991.

5. Carcasci, C. and Facchini, B., ASME J. of Energy Resources Technology, 1996, 118, 36.

6. Oertel, M., Schmitz, J., Weirich, W., Jendryssek-Neumann, D. and Schulten, R., Chem. Eng. Technol., 1987, 10, 248.

7. GE Marine Industrial Engines, LM6000 Gas Turbine, GE Catalog AE-3248 (3/95), 1995.

8. IHI Ishikawajima-Harima Heavy Industries Co Ltd, LM6000 Gas Turbine Generator, IHI Catalog AS-GTE-0079505, 1995.

9. Larson, E. and Hughes, W., Performance modeling of aeroderivative steam-injected gas turbines and combined cycles fueled from fixed or fluid-bed biomass gasifiers, presented at ASME 1996 Turbo-Expo Symposium, paper 96GT-89, 1996.

10. Carcasci, C., Facchini, B. and Marra, R., Modular approach to off-design gas turbine simulation: new prospects for reheat applications, presented at ASME 1996 Turbo-Expo Symposium, Paper 96-GT-395, 1996.

11. Harvey, S. and Kane, N., Analysis of a reheat gas turbine cycle with chemical recuperation using Aspen, in Proceedings, ECOS '96 Symposium, 1996, pp. 297-304.

12. Stambler, I., Gas Turbine World, 1996, May(June), 3643. 